\title{
CRESCIMENTO IN VITRO DE Phalaenopsis H-Sin Sunflower EM DIFERENTES MEIOS DE CULTURA E NÍVEIS DE $\mathrm{pH}^{1}$
}

\author{
Riviane Maria Albuquerque Donha \\ Dauri Aparecido Fadin** \\ Raquel Massaro**** \\ Patrícia Franco Gianini* \\ Cristiano Pedroso-de-Moraes ${ }^{* * * * * *}$
}

RESUMO: As orquídeas se destacam tanto pelo valor ornamental quanto comercial. Entre elas está Phalaenopsis H-Sin Sunflower, uma espécie apreciada mundialmente e com alto valor de mercado. Porém, as Orchidaceae possuem um desenvolvimento vegetativo lento e necessidades específicas, fato que eleva o seu custo de produção e torna indispensável o desenvolvimento de técnicas alternativas. Atualmente, a semeadura in vitro constitui ferramenta importante para propagação das principais espécies de orquídeas. O presente trabalho teve por objetivo estudar aspectos do crescimento in vitro de Phalaenopsis H-Sin Sunflower mediante avaliação do efeito dos meios de cultura $1 / 2 \mathrm{MS}$ e de dois meios a base dos fertilizantes comerciais Hyponex ${ }^{\circledR}\left(\right.$ NPK 6,5-6-19) e Kristalon laranja ${ }^{\circledR}$ (NPK 6-12-36), submetidos a três níveis de $\mathrm{pH}(5,3,5,8$ e 6,3). Para tanto, sementes foram distribuídas em quatro frascos de cada meio e, após 180 dias de cultivo, foram retiradas aleatoriamente vinte plântulas de cada frasco para análise estatística. Foram auferidos os dados referentes à altura das plântulas (AP), comprimento da maior raiz (CMR), comprimento da maior folha (CMF), número de raízes (NR), peso da massa fresca (PMF) e peso da massa seca (PMS). Inferiu-se que o meio de cultura mais eficiente no crescimento de plântulas de Phalaenopsis H-Sin Sunflower foi o meio Hyponex $®$ com nível de $\mathrm{pH}$ de 5,3 que apresentou as maiores médias para todas as variáveis analisadas.

PALAVRAS-CHAVE: Agronegócio; Orchidaceae; Propagação in vitro.

1 Trabalho de conclusão do curso de Especialização em Biotecnologia.

* Discente do Curso de Especialização em Biotecnologia do Centro Universitário Hermínio Ometto (Uniararas). Doutorando do Curso de Produção Vegetal (Unesp/Jabotical), Brasil.

** Técnico Agrícola - Dow AgroScience. Discente do Curso de Especialização em Biotecnologia do Centro Universitário Hermínio Ometto (Uniararas), Brasil.

*** Mestra em Biotecnologia pela Universidade Federal de São Carlos (UFSCar), Brasil.

***** Docente/Técnica do Curso de Especialização em Biotecnologia do Centro Universitário Hermínio Ometto (Uniararas), Brasil.

****** Pós-doutorado em Ecologia Vegetal pela Universidade de Aveiro (Portugal). Docente Assistente de Botânica do Centro Universitário Hermínio Ometto (UNIARARAS), Brasil. E-mail: pedroso@uniararas.br 


\title{
IN VITRO GROWTH OF PHALAENOPSIS H-SIN SUNFLOWER IN DIFFERENT MEDIA AND PH LEVELS
}

\begin{abstract}
Orchids have significant ornamental and commercial values. Phalaenopsis H-Sin Sunflower is a highly appreciated species, worldwide, with significant market value. However, Orchidaceae have slow vegetative development and require specific needs which raises their production costs due to alternative technique employed in their growth. In vitro seeding is an important tool for main orchid species. Current study analyzes in vitro growth aspects of Phalaenopsis $\mathrm{H}$-Sin Sunflower by evaluating the effects of culture medium $1 / 2 \mathrm{MS}$ and in two media based on commercial fertilizers Hyponex ${ }^{\circledR}$ (NPK 6,5-6-19) and Kristalon orange ${ }^{\circledR}$ (NPK 6-12-36), at three $\mathrm{pH}$ levels $(5.3,5.8,6.3)$. Seeds were distributed in four flasks with different media. After 180 days, twenty seedlings were randomly removed from each flask for statistical analysis. Data comprised height of plants (HP), length of larger root (LLR), length of the biggest leaf (LBL), number of roots (NR), weight of fresh mass (WFM) and weight of dry mass (WDM). Results show that the most efficient medium in the growth of Phalaenopsis H-Sin Sunflower seedlings was Hyponex $\AA$, at $\mathrm{pH} 5.3$, with the greatest averages for all variables.
\end{abstract}

KEY WORDS: Agribusiness; Orchidaceae; In vitro propagation.

\section{INTRODUÇÃO}

Com utilidade comercial além do uso ornamental, a família Orchidaceae é considerada uma das maiores entre as angiospermas, apresentando 736 gêneros (CHASE et al., 2015) e 27.801 espécies (GOVAERTS, 2015). Com relação ao Brasil, o mercado de orquídeas amplia-se cada vez mais, podendo ser enfatizada a procura nacional de Phalaenopsis Blume, que desde a década passada destaca-se em vendas, ano após ano (CHONE; OLIVEIRA, 2005), com ênfase a híbridos possuidores de flores amarelas (PEDROSO-DE-MORAES et al., 2007), como Phalaenopsis H-Sin Sunflower.

Tais aumentos em relação à comercialização de Phalaenopsis foram comprovados pela empresa Veiling Holambra, a qual registrou incremento de vendas de até terceira ordem para a cultura, ou seja, em 2001 foram comercializados pelos associados 216.654 vasos da espécie, totalizando $\mathrm{R} \$ 2,3$ milhões, e no ano de 2004 , foram 
comercializados 486.000 vasos, gerando um faturamento anual de $R \$ 7,2$ milhões (CHONE; OLIVEIRA, 2005).

A análise do número de produtores e atacadistas de Phalaenopsis no Brasil demonstra aumento nos últimos cinco anos. Tais produtores juntos chegam a produzir mensalmente de 10 a 35 mil vasos. No entanto, a orquidicultura comercial brasileira ainda é considerada pequena, mas promissora em relação à horticultura intensiva em relação aos agronegócios nacionais (IBRAFLOR, 2013).

A potencialidade do mercado brasileiro pode ser comprovada por dados fornecidos pela IBRAFLOR de que no mês de outubro de 2011, a empresa Veiling Holambra produziu cerca de 302.520 vasos de Phalaenopsis o que corresponde a 39,9\% a mais do que no mesmo mês no ano de 2010. E a mesma empresa, em novembro de 2012, teve a sua produção ainda mais aumentada em 41,7\% quando comparado ao mês de novembro de 2011, o que equivale a 379.799 vasos (IBRAFLOR, 2013).

Com relação à produção em larga escala, para orquídeas, os métodos de germinação in vitro são os mais usuais. Entretanto, as técnicas existentes necessitam de aperfeiçoamento, pois as respostas às condições do cultivo variam fortemente entre gêneros, espécies e até mesmo plantas de um mesmo genótipo cultivadas sob diferentes condições ambientais (CORDEIRO et al., 2011; CUNHA et al.; 2011; DEZAN et al., 2012). O sucesso da semeadura in vitro de orquídeas é dependente do genótipo utilizado (MASSARO et al., 2012), das condições do meio de cultivo, enfatizando-se níveis de pH e nutrientes (CORDEIRO et al., 2011; CUNHA et al., 2011; GUSSON et al., 2012) e de fatores abióticos (PEDROSO-DE-MORAES et al., 2010). Dessa forma, para um desenvolvimento adequado das orquídeas, objetivando redução de custos e alta produtividade, faz-se necessária a combinação ótima entre tais fatores, definindo assim a tecnologia empregada na cultura in vitro (STANCATO et al., 2001).

Assim, o objetivo deste estudo foi avaliar o efeito de diferentes meios de cultura e níveis de $\mathrm{pH}$, no desenvolvimento in vitro do híbrido Phalaenopsis H-Sin Sunflower, visando melhoria no protocolo de propagação massal do híbrido. 


\section{MATERIAL E MÉTODOS}

Para a realização do trabalho, cinco flores de plantas diferentes do híbrido Phalaenopsis H-Sin Sunflower foram autopolinizadas artificialmente em setembro de 2011. Seis meses após a autopolinização, foram coletadas sementes dos frutos maduros, as quais foram levadas ao Laboratório de Botânica e Análises Ambientais do Centro Universitário Hermínio Ometto - Uniararas, Araras (SP), para o início do cultivo in vitro.

Foram preparados três tipos de meios de cultivo, sendo o primeiro composto por MS (MURASHIGE; SKOOG, 1962) com metade da concentração de macronutrientes, o qual foi usado como controle, e os outros dois, por meios compostos pelos fertilizantes Hyponex ${ }^{\circledR}$ (NPK 6,5-6-19) e Kristalon laranja ${ }^{\circledR}$ (NPK 6-12-36) a 2 g.L ${ }^{-1}$. Os meios a base de fertilizantes não sofreram quaisquer acréscimos de micronutrientes. Todos os meios de cultivo foram acrescidos de $1 \mathrm{~g} . \mathrm{L}^{-1}$ de carvão ativado, 30 g.L $\mathrm{L}^{-1}$ de sacarose e tiveram seus $\mathrm{pH}$ ajustados para 5,3, 5,8 e 6,3 antes da adição de 7 g.. ${ }^{-1}$ de ágar-banana. Logo após, $50 \mathrm{~mL}$ de cada meio foram vertidos em quatro frascos de $250 \mathrm{~mL}$ e esterilizados em autoclave a $121^{\circ} \mathrm{C}$ e 1 atm de pressão durante 20 minutos (ARDITTI; ERNEST, 1992).

As sementes foram desinfestadas por imersão em solução de hipoclorito de sódio a 5\%, sendo submetidas à agitação na solução durante cinco minutos, em tubos Eppendorf® (PEDROSO-DE-MORAES et al., 2009a; 2009b). Posteriormente, os tubos foram mergulhados em álcool 70\% e levados à câmara de fluxo laminar, onde as sementes foram lavadas quatro vezes em água destilada com o auxílio de seringa de $1 \mathrm{~mL}$. Ainda utilizando-se da seringa, as sementes juntamente com 1 $\mathrm{mL}$ de água destilada foram depositadas nos frascos contendo os meios de cultivo (ARDITTI; ERNEST, 1992).

Foram semeados quatro frascos por tratamento sendo inoculadas, por recipiente, $1 \mathrm{~g}$ de sementes. Os frascos semeados foram fechados com tampa plástica transparente e mantidos durante 180 dias em câmara climática (B.O.D. MA 403), à temperatura de $25 \pm 2{ }^{\circ} \mathrm{C}$, sob fotoperíodo de 12 horas com intensidade luminosa de aproximadamente $40 \mu \mathrm{mol} . \mathrm{m}^{2} \mathrm{~s}^{-1}$.

Para análise estatística, foram utilizados vinte indivíduos de cada frasco, 
retirados aleatoriamente dos meios de cultura (PEDROSO-DE-MORAES et al., 2009b; CUNHA et al., 2011).

Ao final do trabalho, foram auferidos os dados referentes à altura das plântulas (AP), comprimento da maior raiz (CMR), comprimento da maior folha (CMF), número de raízes (NR), peso da massa fresca (PMF) e peso da massa seca (PMS). Para a análise estatística dos dados foram utilizadas quatro repetições, constituído em um esquema fatorial $3 \times 3$. A comparação entre as médias foi feita pelo teste de Tukey a $5 \%$ de probabilidade. Para as avaliações, os dados foram transformados em arcsen $\sqrt{(X+0,5)}$ visando à estabilização da variância e favorecimento da homogeneidade das amostras (SANTANA; RANAL, 2004).

\section{RESULTADOS E DISCUSSÃO}

Os resultados demonstraram que as plântulas de Phalaenopsis H-Sin Sunflower, cultivadas em meio Hyponex® e pH 5,3, apresentaram as maiores médias para todas as variáveis analisadas quando comparadas aos outros meios de cultivo associados aos demais níveis de $\mathrm{pH}$ (Tabela 1).

Tabela 1. Médias obtidas para as variáveis: Número de raízes (NR), Altura das plântulas (AP), Comprimento da maior raiz (CMR), Comprimento da maior folha (CMF), Peso da massa fresca (PMF) e peso da massa seca (PMS), de plântulas de Phalaenopsis H-Sin Sunflower, cultivadas em três diferentes meios de cultura e níveis de pH. CV (\%) = Coeficiente de variação

(Continua)

\begin{tabular}{|c|c|c|c|c|c|c|}
\hline \multirow{3}{*}{ Meio de cultivo } & \multicolumn{6}{|c|}{$\mathrm{pH}$} \\
\hline & 5,3 & 5,8 & 6,3 & 5,3 & 5,8 & 6,3 \\
\hline & \multicolumn{3}{|c|}{ NR } & \multicolumn{3}{|c|}{$\mathrm{AP}(\mathrm{cm})$} \\
\hline $1 / 2 \mathbf{M S}$ & $2,11 \mathrm{Ba}$ & $2,13 \mathrm{Ba}$ & $1,72 \mathrm{Bb}$ & $4,02 \mathrm{Ba}$ & $3,45 \mathrm{Bb}$ & $3,19 \mathrm{Bc}$ \\
\hline Hyponex & $3,14 \mathrm{Aa}$ & $2,81 \mathrm{Ab}$ & $2,79 \mathrm{Ab}$ & $4,51 \mathrm{Aa}$ & $4,11 \mathrm{Ab}$ & $3,93 \mathrm{Ac}$ \\
\hline Kristalon & $1,19 \mathrm{Ca}$ & $1,21 \mathrm{Ca}$ & $1,11 \mathrm{Cb}$ & $3,87 \mathrm{Ca}$ & $3,14 \mathrm{Cb}$ & $3,03 \mathrm{Cc}$ \\
\hline F - Mc & & $17,8^{* *}$ & & & $20,1^{*}$ & \\
\hline $\mathrm{F} \cdot \mathrm{pH}$ & $12,9^{*}$ & & & & $14,6^{* *}$ & \\
\hline F - Mc x pH & & $12,4^{* *}$ & & $12,7^{*}$ & & \\
\hline CV (\%) & & 9,3 & & 11,2 & & \\
\hline
\end{tabular}


(Conclusão)

\begin{tabular}{|c|c|c|c|c|c|c|}
\hline \multirow{3}{*}{ Meio de cultivo } & \multicolumn{6}{|c|}{$\mathrm{pH}$} \\
\hline & 5,3 & 5,8 & 6,3 & 5,3 & 5,8 & 6,3 \\
\hline & \multicolumn{3}{|c|}{ NR } & \multicolumn{3}{|c|}{$\mathrm{AP}(\mathrm{cm})$} \\
\hline & \multicolumn{3}{|c|}{ CMR (cm) } & \multicolumn{3}{|c|}{$\mathrm{CMF}(\mathrm{cm})$} \\
\hline $1 / 2 \mathbf{M S}$ & $1,63 \mathrm{Ba}$ & $1,49 \mathrm{Bb}$ & $1,36 \mathrm{Bc}$ & $1,43 \mathrm{Ba}$ & $1,31 \mathrm{Bb}$ & $1,19 \mathrm{Bc}$ \\
\hline Hyponex & $1,75 \mathrm{Aa}$ & $1,61 \mathrm{Ab}$ & $1,52 \mathrm{Ac}$ & $1,54 \mathrm{Aa}$ & $1,41 \mathrm{Ab}$ & $1,31 \mathrm{Ac}$ \\
\hline Kristalon & $1,32 \mathrm{Ca}$ & $1,21 \mathrm{Cb}$ & $1,04 \mathrm{Cc}$ & $1,43 \mathrm{Ba}$ & $1,32 \mathrm{Bb}$ & $1,07 \mathrm{Cc}$ \\
\hline F - Mc & & $12,4^{*}$ & & & $18,3^{* *}$ & \\
\hline $\mathrm{F} \cdot \mathrm{pH}$ & & $13,9^{*}$ & & & $12,5^{*}$ & \\
\hline F - Mc x pH & $5,2^{* *}$ & & & $10,6^{*}$ & & \\
\hline \multirow[t]{2}{*}{ CV (\%) } & 8,12 & & & & 11,45 & \\
\hline & \multicolumn{3}{|c|}{ PMF (g) } & \multicolumn{3}{|c|}{ PMS (g) } \\
\hline $1 / 2$ MS & $0,41 \mathrm{Ba}$ & $0,30 \mathrm{Bb}$ & $0,19 \mathrm{Bc}$ & $0,20 \mathrm{Ba}$ & $0,11 \mathrm{Bb}$ & $0,03 \mathrm{Bc}$ \\
\hline Hyponex & $0,54 \mathrm{Aa}$ & $0,43 \mathrm{Ab}$ & $0,30 \mathrm{Ac}$ & $0,32 \mathrm{Aa}$ & $0,21 \mathrm{Ab}$ & $0,09 \mathrm{Ac}$ \\
\hline Kristalon & $0,29 \mathrm{Ca}$ & $0,19 \mathrm{Cb}$ & $0,18 \mathrm{Bb}$ & $0,21 \mathrm{Ba}$ & $0,12 \mathrm{Bb}$ & $0,04 \mathrm{Bc}$ \\
\hline F $=M c$ & & $12,6^{*}$ & & & $14,8^{* * *}$ & \\
\hline $\mathbf{F} \cdot \mathbf{P h}$ & & $11,3^{*}$ & & & $11,3^{*}$ & \\
\hline F $-\mathbf{M c} \times \mathbf{p H}$ & & $11,9^{*}$ & & & $17,1^{*}$ & \\
\hline CV (\%) & & 17,32 & & & 11,93 & \\
\hline
\end{tabular}

Médias seguidas por letras iguais não diferem entre si pelo teste de Tukey a 5\% de probabilidade. Letras maiúsculas representam análise nas colunas e minúsculas nas linhas. * significativo à $p<0,05$; ** significativo à $p<0,01 ; \mathrm{ns}=$ não significativo.

As sementes de orquídeas podem germinar e/ou se desenvolverem bem em valores de pH entre 3,6 e 7,6 (ARDITTI; ERNST, 1984; LEIFERT et al., 1992a). Entretanto, a faixa que revela o melhor ajuste é a de 5,0 a 6,5 para um crescimento adequado da maioria das espécies pertencentes aos gêneros Cattleya, Cymbidium, Laelia e Oncidium (PIERIK, 1987; KÄMPF, 2000). Dessa forma, existe consenso no fato de que meios de cultivo levemente ácidos têm favorecido o desenvolvimento de orquídeas (ARDITTI, 1977; LEIFERT et al., 1992b).

A análise pormenorizada de cada variável analisada permitiu, primeiramente, a constatação de que em relação à variável número de raízes (NR), os maiores 
valores obtidos na interação entre o meio de cultivo à base de fertilizante Hyponex e pH 5,3 estão de acordo com os resultados encontrados para a orquídea híbrida Cymbidium Swartz, para a qual o mesmo nível de $\mathrm{pH}$ favoreceu a rizogênese e consequentemente o aumento do NR por plântulas, por ter facilitado uma melhor absorção de nutrientes (SILVA et al., 2006). Contudo, para Miltonia flavescens Lindl. (Orchidaceae), diferentes níveis de $\mathrm{pH}$ não apresentaram significância estatística para a variável NR (STEFANELLO et al., 2009). Ainda, assim como para este trabalho, é relatado que para as orquídeas Cattleya loddigesii Lindl., Cattleya tigrina Lindl., Laelio cattleya schilleriana Rolfe e Schomburgkia gloriosa Lindl., plantas germinadas em meio de cultivo à base de fertilizante Hyponex® apresentaram os melhores resultados estatísticos para a NR devido à percentagem mais baixa de nitrogênio amoniacal encontrada no fertilizante Hyponex, em relação ao meio MS e ao fertilizante Kristalon, permitir maior rizogênese (PEDROSO-DE-MORAES et al., 2009a; 2009b; CUNHA et al., 2011; DEZAN et al., 2012).

Com relação à variável comprimento da maior raiz (CMR), é válido salientar que mesmo que a interação supracitada tenha apresentado os maiores valores médios na análise estatística realizada, tal incremento em comprimento pode ser horticulturalmente indesejado, uma vez que o tipo do sistema radicial, obtido no enraizamento in vitro também determina o sucesso do transplante, sendo as raízes mais curtas as mais adequadas por se encontrarem em crescimento ativo, facilitando a aclimatização da planta (GRATTAPAGLIA; MACHADO, 1998; STEFANELLO et al., 2009). Nesse ínterim é importante a observação de que a utilização do fertilizante Hyponex ${ }^{\circledR}$ como base de meios de cultivo, assim como neste trabalho, permitiu um maior crescimento de raízes em plântulas analisadas das orquídeas híbridas $C a$ ttleya amethysto glossa X (Cattleya dupreana X Laelia purpurata) e Lc.schilleriana (CORDEIRO et al., 2011; CUNHA et al., 2011).

A análise da variável altura da plântula (AP) demonstrou que os resultados encontrados na interação diferem dos descritos para a orquídea $M$. flavescens, para a qual não houve significância estatística encontrada para os diferentes níveis de $\mathrm{pH}$ utilizados em relação à AP (STEFANELLO et al., 2009). Entretanto, para o comprimento da maior folha (CMR), a interação apresenta concordância para híbrido de Cymbidium (SILVA et al., 2006) em relação ao exato nível de pH e é corroborado 
pelos melhores resultados médios encontrados em níveis de $\mathrm{pH}$ mais baixos para o desenvolvimento e crescimento in vitro da orquídea Nephrolepisbiserrata (Sw.) Schott. (AMBRÓSIO; MELO, 2004). Além disso, o híbrido Lc. schilleriana também apresentou as maiores médias para as duas variáveis supracitadas ao ser cultivado em meio Hyponex® (CUNHA et al., 2011).

Os maiores valores para o peso de matéria fresca (PMF) e seca (PMS) são corroborados por trabalhos recentes enfocando germinação e regeneração in vitro de representantes da família Orchidaceae cultivados em meios com níveis de $\mathrm{pH}$ variando de 5,0 a 5,8 (CHAPLA et al., 2009; PEDROSO-DE-MORAES et al., 2009; SUZUKI et al., 2009; BESSON et al., 2010; SOUTO et al., 2010; CHIU et al., 2011; CUNHA et al., 2011; LIAO et al., 2011), com exceção dos geralmente utilizados para cultivo de orquídeas do gênero Phalaenopsis Blume, para a qual é descrito em metodologias a utilização de pH 5,4 (CHEN et al., 2000; MURDAD et al., 2010). Com relação ao meio de cultivo, assim como para este trabalho, o meio Hyponex ${ }^{\circledR}$, quando comparado com os demais, permitiu a obtenção de maiores valores médios para as variáveis PMF e PMS para o híbrido Lc. Schilleriana (CUNHA et al., 2011).

\section{CONCLUSÃO}

O meio de cultivo à base do fertilizante Hyponex ${ }^{\circledR}$, associado ao nível de pH 5,3, mostrou-se mais adequado para o cultivo in vitro de Phalaenopsis H-Sin Sunflower.

\section{REFERÊNCIAS}

AMBRÓSIO, S. T.; MELO, N. F. de. Interaction between sucrose and pH during in vitro culture of Nephrolepisbiserrata (Sw.) Schott (Pteridophyta). Acta Botanica Brasílica, São Paulo, v. 18, n. 4, p. 809-813, 2004.

ARDITTI, J.; ERNST, R. Physiology of germinating orchid seeds. In: ARDITTII, J.

(Ed.) Orchid biology: reviews and perspectives III. New York: Cornell University Press, 1984. p. 177-222. 
ARDITTI, J. Clonal propagation of orchids by means of tissue culture: a manual. In: ARDITTI, J. (ed.). Orchid biolog y: reviews and perspectives. New York: Cornell University, 1977. v. 1, p. 203-293.

ARDITTI, J.; ERNEST, R. Micropropagation of orchids. New York: John Wiley \& Sons, 1992, 682p.

BESSON, J. C. F.; OLIVEIRA, L. K.; BONETT, L. P.; STEFANELLO, S. Fontes e concentrações de carboidratos no crescimento vegetativo e no enraizamento in vitro de Miltonia flavescens Lindl. Revista Brasileira de Biociências, Porto Alegre, v. 8, p. 9-13, 2010.

CHAPLA, P. I.; BESSON, J. C. F.; OLIVEIRA, L. K.; SILVA, J. M. da; ROCHA, A. C. de S.; STEFANELLO, S. pH, carvão ativado e agentes gelelificantes do meio de cultura no crescimento in vitro de Miltonia flavescens Lindl. Plant Cell Culture \& Micropopagation, v. 5, p. 87-93, 2009.

CHASE, M. W.; CAMERON, K. M.; FREUDENSTEIN, J. V.; PRIDGEON, A. M.; SALAZAR, G.; VAN DEN BERG, C.; SCHUITEMAN,A. An updated classification of Orchidaceae. Botanical Journal of the Linnean Society, v. 177, p. 151-174, 2015.

CHEN, Y. C.; CHANG, C.; CHANG, W. C. A reliable protocol for plant regeneration from callus culture of Phalaenopsis. In Vitro Cellular and Developmental Biology-Plant, v. 36, p. 420-423, 2000.

CHIU, Y. T.; LIN, C. S.; CHANG, C. In vitro frutificação e produção de sementes em Erycinapusilla (L.) NH Williams e MW Chase. Propagation of ornamental plants, v. 11, p. 131-136, 2011.

CHONE, R. M. S.; OLIVEIRA, L. H. Desenho e Análise da Cadeia Produtiva de Plantas Ornamentais: o caso das Orquídeas do gênero Phalaenopsis. In: INTERNATIONAL MEETING OF THE IBEROAMERICAN ACADEMY OF MANAGEMENT. "MANAGEMENT, KNOWLEDGE AND FLEXIBILITY”, 4., 2005, Lisboa. Anais [...]. Lisboa, 2005. p. 8-11.

CORDEIRO, G. M.; PEDROSO-DE-MORAES, C.; MASSARO, R.; CUNHA, T. Desenvolvimento in vitro de Cattleya amethystoglossa Lindley $\mathrm{X}$ (Cattleya 
dupreana X Laelia purpurata Lindley) em diferentes meios de cultura. Revista Científica Eletrônica de Agronomia, v. 18, p. 22-28, 2011.

CUNHA, T.; CORDEIRO, G. M.; MASSARO, R.; DEZAN, L. F.; PEDROSO-DE-MORAES, C. Desenvolvimento in vitro de Laeliocattleya schilleriana Rolfe em meios de cultivo simplificados. Scientia Plena, v. 7, p. 1-5, 2011.

DEZAN, L. F.; CANASSA, F.; SOUZA-LEAL, T. S.; DIOGO, J. A.; MASSARO, R.; CORDEIRO, G. M.; PEDROSO-DE-MORAES, C. Crescimento in vitro de Schomburgkia gloriosa Lindl. em meio de cultivo simplificados. Idesia (Arica), v. 30, p. 53-58, 2012.

GOVAERTS, R. H. A. The PlantList. Disponível em: http:// www.theplantlist.org. Acesso em: 01 set. 2015.

GRATTAPAGLIA, D.; MACHADO, M. A. Micropropagação. In: TORRES, A. C.; CALDAS, L. S.; BUSO, J. A. Cultura de tecidos e transformação genética de plantas. Brasília: Embrapa-SPI/Embrapa-CNPH, 1998. v. 1, p. 87-132.

GUSSON, R. R.; PEDROSO-DE-MORAES, C.; RONCONI, C. C. Diferentes concentrações de carvão ativado no crescimento e enraizamento in vitro de Cattleya pumila Hook. Rama: Revista em Agronegócio e Meio Ambiente, v. 5, p. 551-563, 2012.

IBRAFLOR. Disponível em: http://www.ibraflor.com/publicacoes/vw.php?cod=189 Acesso em: 15 fev. 2013.

KÄMPF, A. N. Seleção de materiais para uso como substrato. In: KÄMPF, A. N.; FERMINO, M. H. (Ed). Substrato para plantas: a base da produção vegetal em recipientes. Porto Alegre: Genesis, 2000. p. 139-145.

LEIFERT, C.; CAMOTTA, H.; WAITES, W. M. Effect of combination of antibiotics on micropropagated Clematis, Delphinium, Hosta, Iris and Photinia. Plant Cell, Tissue and Organ Culture, v. 29, p. 153-160, 1992a.

LEIFERT, C.; PRYCE, S.; LUMSDEN, P. J.; WAITES, W. M. Effect of medium acidity on growth and rooting of different plant species growing in vitro. Plant Cell Tissue and Organ Culture, v. 30, p. 171-179, 1992b. 
LIAO, Y. J.; TSAI, Y. C.; SUN, Y. W.; LIN, R. S.; WU, F. S. In vitro shoot induction and plant regeneration from flower buds in Paphiopedilum orchids. In Vitro Cellular \& Developmental Biology, v. 47, p. 702-709, 2011.

MASSARO, R.; SOUZA-LEAL, T.; CORDEIRO, G. M.; PEDROSO-DE-MORAES, C. Desenvolvimento in vitro de Epidendrum secundum Jacq. em meios de cultivo simplificados. Rama: Revista em Agronegócio e Meio Ambiente, v. 5, p. 337-351, 2012.

MURASHIGE, T.; SKOOG, F. A revised medium for rapid growth and bio-assays with tobacco tissue cultures. Physiologia Plantarum, v. 15, p. 473-497, 1962.

MURDAD, R.; LATIP, M. A.; AZIZ, Z. A.; RIPIN, R. Effects of carbon source and potato homogenate on in vitro growth and development of Sabah's endangered orchid: Phalaenopsisgigantea. Ásia - Pacific Journal of Molecular Biology and Biotechnology, v. 18, p. 199-202, 2010.

PEDROSO-DE-MORAES, C.; DOMINGUES, E.; PREZZI, L. E.; SOUZA-LEAL, T.; ZAMBON, R. L.; BRESCANSIN, R. L.; RAMOS, P. A. B. Florística e fitossociologia da família Orchidaceae no Centro de Educação Ambiental "Francisco Mendes", município de Mogi Guaçu, SP, Brasil. Scientia Plena, v. 6, p. 1-5, 2010.

PEDROSO-DE-MORAES, C.; MOURA, E. R. R.; SILVA, M. C.; ABDALLA, M. A. As orquídeas e o mercado. Boletim CAOB, v. 66, p. 36-42, 2007.

PEDROSO-DE-MORAES, C.; DIOGO, J. A.; PEDRO, N. P.; CANABRAVA, R. I.; MARTINI, G. A.; MARTELINE, M. A. Desenvolvimento in vitro de Cattleya loddigesii Lindley (Orchidaceae) utilizando fertilizantes comerciais. Revista Brasileira de Biociências, v. 7, p. 67-69, 2009a.

PEDROSO-DE-MORAES, C.; SANTOS, N. S.; MASSARO, R.; CORDEIRO, G. M.; SOUZALEAL, T. Desenvolvimento in vitro de Cattleya tigrina A. Richard (Orchidaceae) utilizando fertilizantes comerciais. Ensaios e Ciência, v. 13, p. 57-65, 2009 b.

PIERIK, R. L. M. In vitro culture of higher plants. Dordrecht: Martinus Nyhoff, 1987. 344p. 
SANTANA, D. G.; RANAL, M. A. Análise da Germinação: um enfoque estatístico. Brasília: Universidade de Brasília, 2004, 229p.

SILVA, J. A. T. da; CHAN, M. T.; CHAI, M. T.; TANAKA, M. Priming abiotic factors for optimal hybrid Cymbidium (Orchidaceae) PLB and callus induction, plantlet formation, and their subsequent cytogenetic stability analysis. Scientia Horticulturae, v. 109, n. 4, p. 368-378, 2006.

SOUTO, J. S.; MORIMOTO, J. M.; FERREIRA, W. M.; NAKABASHI, M.; SUZUKI, R. M. Efeitos do ácido naftalenoacético no desenvolvimento in vitro de Cattleya bicolor Lindl. (Orchidaceae). Revista Brasileira de Biociências, v. 8, p. 179-185, 2010.

STANCATO, G. C.; BEMELMANS, P. F.; VEGRO, C. L. R. Produção de mudas de orquídeas a partir de sementes in vitro e sua viabilidade econômica: estudo de caso. Revista Brasileira de Horticultura Ornamental, v. 17, p. 25-33, 2001.

STEFANELLO, S.; KARSTEN, J.; MÜLLER, T. S.; TOMCZAK, A. P.; BONETT, L. P.; SCHUELTER, A. R. Conversão in vitro de raízes e folhas de Miltonia flavescens Lindl. em protocormos e regeneração de plantas. Ciência e Agrotecnologia. v. 33, p. 53-59, 2009.

SUZUKI, R. M.; MOREIRA, V. C.; NAKABASHI, M.; FERREIRA, W. M. Estudo da germinação e crescimento in vitro de Hadrolaelia tenebrosa (Rolfe) Chiron \& V. P. Castro (Orchidaceae), uma espécie da flora brasileira ameaçada de extinção. Hoehnea, v. 36, p. 657-666, 2009.

Recebido em: 18/10/2014

Aceito em: 05/11/2017 